\title{
Correlation between Protein-with-Molecular-Weight-53 (p53), Burkit Cell Lymphoma 2 (BC/2), and Fas Ligand (FasL) and Vascular-Cell-Adhesion- Molecule-1 (VCAM-1) mRNA Expression Levels in a Pathogenesis Study of Preeclampsia
}

\author{
Mintareja Teguh, ${ }^{1}$ Made Kornia Karkata, ${ }^{2}$ Firman Fuad Wirakusumah, ${ }^{3}$ Johanes Cornelius Mose, ${ }^{3}$ \\ Mieke Hemiawati Satari, ${ }^{4}$ Leri Septiani ${ }^{3}$ \\ ${ }^{1}$ Department of Obstetrics and Gynecology, Faculty of Medicine, Universitas Udayana-Karangasem Hospital \\ ${ }^{2}$ Department of Obstetrics and Gynecology, Faculty of Medicine, Universitas Udayana-Sanglah Hospital \\ ${ }^{3}$ Department of Obstetrics and Gynecology, Faculty of Medicine, Universitas Padjadjaran-Dr. Hasan Sadikin \\ General Hospital \\ ${ }^{4}$ Faculty of Dentistry, Universitas Padjadjaran
}

\begin{tabular}{|c|c|}
\hline Abstract & $\begin{array}{l}\text { Objective: To determine the role of protein-with-molecular-weight- } 53 \text { ( } p 53) \text {, } \\
\text { burkit cell lymphoma } 2(B c / 2) \text {, Fas ligand (Fas } L \text { ) mRNA, and vascular cell adhesion } \\
\text { molecule } 1 \text { (VCAM-1), known as the apoptosis-related molecular pathway, in } \\
\text { preeclamptic patients. }\end{array}$ \\
\hline & $\begin{array}{l}\text { Methods: Observation on the correlation between the mRNA levels of } p 53 \text {, } \\
B c / 2 \text { and FasL and VCAM- } 1 \text { in } 31 \text { subjects at } 28-42 \text { weeks gestational age was } \\
\text { performed in this study using the real time reverse transcriptase-polymerase } \\
\text { chain reaction (RT-PCR). }\end{array}$ \\
\hline & $\begin{array}{l}\text { Results: The results showed that } p 53 \mathrm{mRNA} \text { increased }(>1.2350 \mathrm{ng} / \mu \mathrm{L}) \text { in the } \\
\text { preeclampsia group compared to the normal pregnancy group }(p=0.010) \text {, } \\
\text { Bcl } 2 \text { mRNA was lower }(\leq 0.9271 \mathrm{ng} / \mu \mathrm{L}) \text { in the preeclampsia group than the } \\
\text { control group }(p=0.041) \text {. There was also a tendency of increased FasL mRNA } \\
\text { expression }(>0.5509 \mathrm{ng} / \mu \mathrm{L}) \text { in the preeclampsia group compared to the normal } \\
\text { pregnancy group }(p=0.300) \text {. The level of VCAM- } 1 \text { elevated }(>890.08 \mathrm{ng} / \mathrm{mL}) \text { in } \\
\text { the preeclampsia group compared to the normal pregnancy group }(p=0.001) \text {. } \\
\text { In preeclampsia, the correlation between the } B c / 2 / p 53 \text { ratio and VCAM-1 was } \\
r=0.541(p=0.002) \text {, whereas the correlation in normal pregnancy was } r=0.099 \\
(p=0.595) \text {. }\end{array}$ \\
\hline $\begin{array}{l}\text { Received: } \\
\text { April 16, } 2013\end{array}$ & $\begin{array}{l}\text { Conclusions: There are correlations between the mRNA expression levels of } p 53 \\
\text { and } B c / 2 \text { as an intrinsic pathway of apoptosis along with the VCAM-1 levels in the } \\
\text { incidence of preeclampsia. However, no correlation is found between FasL mRNA } \\
\text { expression and the incidence of preeclampsia. }\end{array}$ \\
\hline $\begin{array}{l}\text { Revised: } \\
\text { June 12, } 2013\end{array}$ & Keywords: Bc/2, FasL, p53, preeclampsia, VCAM-1 \\
\hline $\begin{array}{l}\text { Accepted: } \\
\text { April 10, } 2014\end{array}$ & IJIHS. 2014;2(1):23-9 \\
\hline
\end{tabular}

\section{Introduction}

Preeclampsia in pregnancy is characterized by blood pressure of $\geq 140 / 90 \mathrm{mmHg}$ in two or more measurements which is accompanied by proteinuria $(30 \mathrm{mg} / \mathrm{dL}$ ) in two separate tests with a nominal measurement scale. There are

Correspondence:

Mintareja Teguh, Department of Obstretics and Gynecology, Faculty of Medicine, Universitas UdayanaKarangasem Hospital

Jl. Ngurah Rai No. 58, Amlapura 80811, Bali, Indonesia e-mail: mintareja.teguh@gmail.com three stages involved in the pathogenesis of preeclampsia: abnormal vascular remodeling of placenta, placental ischemia, and endothelial cell dysfunction. ${ }^{1}$ Some previous studies have hypothesized that the causes of preeclampsia originally involve genetic, immunological, and other factors resulting in a failure in trophoblast proliferation and invasion. These factors lead to abnormal placental vascular remodeling and endothelial dysfunction, causing the syndrome of preeclampsia.

Protein-with molecular weight-53, or p53, protects cells against the deoxyribonucleic acid 
(DNA) damage. ${ }^{2}$ DNA damage and hypoxia, which increases the phosphorylation of p53, occur when metabolic processes enhance the role of p53 and decrease murine double minute-2 protein (MDM-2) that will ultimately enhance the role of p53 in apoptosis. ${ }^{2-4}$ However, the biosynthetic mechanisms associated with p53 and apoptosis in pregnancy are not known. ${ }^{2,5}$

In the intrinsic pathway of apoptosis, the mitochondrial genes are primarily regulated by burkit cell lymphoma $2(B c / 2)$. Tissue samples from patients with preeclampsia have shown that the expression of the antiapoptotic protein $\mathrm{Bcl} 2$ is lower than that of patients with normal pregnancy. Increased apoptotic activity in the placental bed of preeclampsia patients inhibits trophoblast invasion into the spiral artery. ${ }^{6}$

The ligand receptor pathway, or the extrinsic pathway, is mediated by cytokines such as the tumor necrotic factor alpha (TNF $\alpha$ ) and Fas ligand (FasL). FasL/Fas plays an important role in protecting the fetus from the maternal immune system. In mouse experiments, FasL played a role to prevent changes in immune cell activation between the maternal-fetal surface. This showed a decreased expression of FasL on the surface of decidual leukocyte infiltration and enhanced placental fetal death. ${ }^{6,7}$

The number of markers indicating endothelial dysfunction increase in the blood or urine of preeclamptic women. Most of these markers, including the vascular cell adhesion molecule 1 (VCAM-1) and cellular fibronectin, increase during several weeks of pregnancy. Placental ischemia occurs due to hypoxia, which is presumed to be related to the vascular endothelial damage. This condition is characterized by increased levels of VCAM-1. Increased levels of VCAM-1 improve the regulation of the apoptotic caspase cascade. The apoptosis that occurs in preeclampsia may occur through the intrinsic and extrinsic pathways. The role of $p 53, B c / 2$, and FasL messenger ribonucleic acid (mRNA) in apoptosis in preeclampsia and the uncertainty in which apoptotic pathway

Table 1 Characteristic of Research Subjects

\begin{tabular}{|c|c|c|c|c|}
\hline \multirow{2}{*}{ Variable } & \multicolumn{2}{|c|}{ Group } & \multicolumn{2}{|c|}{ Significance } \\
\hline & Preeclampsia $(n=31)$ & Control (n=31) & $X^{2} / t$ & p Value \\
\hline Maternal age (yrs.) & & & 0.000 & $1.000 *)$ \\
\hline$<20$ & 3 & 3 & & \\
\hline $20-34$ & 21 & 21 & & \\
\hline$\geq 35$ & 7 & 7 & & \\
\hline Mean & 29.29 (7.98) & $29.61(7.40)$ & & \\
\hline Median & $18-45$ & $18-44$ & & \\
\hline Gestational age (wks.) & & & 1.409 & $0.600 *)$ \\
\hline $28-32$ & 1 & 0 & & \\
\hline $33-37$ & 8 & 8 & & \\
\hline $38-42$ & 22 & 23 & & \\
\hline Mean & 37.87 (1.56) & $38.23(0.88)$ & & \\
\hline Median & $31-40$ & $37-40$ & & \\
\hline Parity & & & 0.862 & $0.654 *)$ \\
\hline $0-1$ & 17 & 17 & & \\
\hline $2-3$ & 10 & 12 & & \\
\hline$\geq 4$ & 4 & 2 & & \\
\hline BMI $\left(\mathrm{kg} / \mathrm{m}^{2}\right)$ & & & 0.595 & $0.554 * *)$ \\
\hline Mean & 22.77 (2.93) & $22.27(3.66)$ & & \\
\hline Median & $15-31$ & $18-29$ & & \\
\hline
\end{tabular}

BMI, body mass index; Statistical test ${ }^{*}$ )Chi-square and ${ }^{* *}$ )Independent $\mathrm{t}$ 
used have prompted further studies. This study aimed to determine the role of $p 53, B c / 2$, and FasL mRNA and VCAM-1 in preeclampsia.

\section{Methods}

\section{Research Subjects}

Pregnant women who visited Dr. Hasan Sadikin General Hospital, as well as its teaching hospital network (Cibabat Hospital and Astana Anyar Maternity Hospital) at 28-42 weeks gestational age and who were diagnosed with preeclampsia (according to the protocol of the Division of Feto-maternal Department of Obstetrics and Gynecology, Dr. Hasan Sadikin General Hospital, Faculty of Medicine, Universitas Padjadjaran, Bandung, Indonesia, 2008) served as the case group. To comply with the approval from the Ethical Committee of Dr. Hasan Sadikin General Hospital, informed consent was obtained from every single participant in this study. Statistical calculations were obtained from a sample size of 31 patients for both the case and control groups from July 2009-April 2010.
The specimens were taken from the placental tissue, immediately after the placenta was born. Using tweezers and a scalpel, the placental tissue was cut approximately $2 \times 2 \mathrm{~cm}$ in size and put in a sterile tube and received label for the RNA expression inspection: $p 53, B c / 2$ and FasL in real time-polymerase chain reaction (PCR). The placental specimens were immediately frozen in liquid nitrogen, then stored in the freezer with a temperature of $-80^{\circ} \mathrm{C}$ until it was used.

\section{Clinical examination}

The physical examination performed in this study included the general condition, weight, height, as well as a heart and lung examination. Systolic and diastolic blood pressure were also measured after the patient rested for 15 minutes on her left side. The blood pressure was the average of two examinations performed at 5-minute intervals.

\section{Determination of VCAM-1 levels}

The levels of VCAM-1 protein were determined in duplicate experiments by using the enzymelinked immunosorbent assay (ELISA) with the human VCAM-1 immunoassay kit (Quantikine) in

Table 2 Relationship between High-Low Expression of mRNA; p53; Bcl2 and FasL and the Level of VCAM-1 in Preeclampsia

\begin{tabular}{|c|c|c|c|c|c|}
\hline \multirow{2}{*}{ Variable } & \multicolumn{2}{|c|}{ Group } & \multirow[b]{2}{*}{$x^{2}$} & \multicolumn{2}{|c|}{ Significance } \\
\hline & Preeclampsia (=31) & Control (n=31) & & p Value & OR $(95 \% \mathrm{Cl})$ \\
\hline \multicolumn{6}{|l|}{ 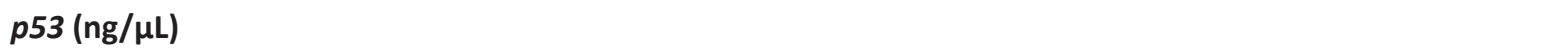 } \\
\hline Mean & $1.18(0.32)$ & $1.08(0.17)$ & & & \\
\hline$>1.2350$ & 13 & 4 & 6.565 & 0.000 & 4.87 (1.37-17.35) \\
\hline$\leq 1.2350$ & 18 & 27 & & & \\
\hline \multicolumn{6}{|l|}{$B c / 2$ (ng/ $\mu \mathrm{L})$} \\
\hline Mean & $0.84(0.18)$ & $0.95(0.20)$ & & & \\
\hline$\leq 0.9271$ & 18 & 10 & 4.168 & 0.041 & $2.91(0.92-9.43)$ \\
\hline$>0.9271$ & 13 & 21 & & & \\
\hline \multicolumn{6}{|l|}{ FasL (ng/ $\mu \mathrm{L})$} \\
\hline Mean & $0.69(0.28)$ & $0.64(0.32)$ & & & \\
\hline$>0.5509$ & 21 & 16 & 1.072 & 0.300 & $0.51(0.18-1.42)$ \\
\hline$\leq 0.5509$ & 10 & 15 & & & \\
\hline \multicolumn{6}{|c|}{ VCAM-1 (ng/mL) } \\
\hline Mean & $1077,63(413.88)$ & $823.99(271.48)$ & & & \\
\hline$>890.08$ & 23 & 10 & 10.949 & 0.001 & $6.04(2.01-18.17)$ \\
\hline$\leq 890.08$ & 8 & 21 & & & \\
\hline
\end{tabular}

Statistical, Chi-square test; Determination cut-off for $p 53, B c / 2$, FasL and VCAM-1 based on Receiver Operating Characteristics Curve (ROC) 
Correlation between Protein-with-Molecular-Weight-53 (p53), Burkit Cell Lymphoma 2 (Bc/2), and Fas Ligand (FasL) and Vascular-Cell-Adhesion Molecule-1 (VCAM-1) mRNA Expression Levels of in a Pathogenesis Study of Preeclampsia

accordance with the manufacturer's instructions (R \& D Systems Inc., Minneapolis, MN). The ELISA kit is based on a solid phase sandwich ELISA that consists of anti-VCAM-1 polyclonal antibody and perioxidase conjugated anti-VCAM-1 polyclonal antibody. The concentration of VCAM-1 in each preparation was determined using the standard curve available.

RNA isolation and cDNA synthesis

Total RNA was extracted from fresh frozen sections with RNeasy Mini kit (Qiagen, Hilden, Germany) in accordance with the instructions from the manufacture. The isolated RNA quantity was measured by a ND-1000 spectrophotometer (NanoDrop Tech., Wilmington, Delaware). The template cDNA was synthesized from 13.5 $\mu \mathrm{g}$ of total RNA using the Omniscript Reverse Transcriptase kit (Qiagen), random primer (hexadeoxyribonucleotide mixture, Takara, Shiga, Japan), and ribonuclease inhibitor (Porcine liver, Takara). Total RNA was reverse transcribed with $4 \mathrm{U}$ of Omniscript reverse transcriptase in $20 \mu \mathrm{L}$ reaction volume $\left(60\right.$ minutes at $37^{\circ} \mathrm{C}, 5$ minutes at $93^{\circ} \mathrm{C}$, and finally put on ice). Resulting cDNA samples were then stored at $-30{ }^{\circ} \mathrm{C}$ until the analysis was performed.

Real time reverse transcriptase-polymerase chain reaction ( $R T-P C R$ )

Real-time RT-PCR analyses were performed using the $A B I$ Prism 7000 Sequence detection system (Applied Biosystems, Foster City, CA). The standard reaction volume was $20 \mu \mathrm{L}$ and the PCR kit used was Go Green Master Mix-Taq (Promega, Madison), $5.0 \mu \mathrm{L}$ of cDNA template, and $4 \mu \mathrm{M}$ of both forward and reverse primers. The initial step of PCR was pre-heated at approximately $95{ }^{\circ} \mathrm{C}$ for 3 minutes; denaturated for 39 cycles at $95{ }^{\circ} \mathrm{C}$ for 30 seconds, annealed at $55^{\circ} \mathrm{C}$ for 1 minute, and extended at $72{ }^{\circ} \mathrm{C}$ for 1 minute with additional final extension at $72{ }^{\circ} \mathrm{C}$ for 10 minutes. The p53 fragment was 741 base pairs (bp). Glyceraldehydes-3-phosphate dehydrogenase (GAPDH) was used for normalization. The $p 53$ fragment was isolated using 5'AGA GTC TAT AGG CCC ACC CC3' forward primer and 5'GCT CGA CGC TAG GAT CTG AC3' reverse primer following the reseach of Ohtani. ${ }^{8}$ The $B c / 2$ fragment was isolated using 5'GAC AGA AGA TCA TGC CGT CC3' forward primer and 5'GGT ACC AAT GGC ACT TCA AG3', the $B C / 2$ fragment was $76 \mathrm{bp}$, reverse primer based on the research by Mbazima. ${ }^{9}$ The FasL fragment was isolated using 5'GCA GCC CTT CAA TTA CCC AT3' forward primer and 5'CAG AGG TTG GAC AGG GAA GAA3', the FasL fragment was $101 \mathrm{bp}$, reverse primer based on the research by Das. ${ }^{10}$

\section{Data analysis}

The statistical analyses used were Shapiro-Wilk test, independent t test, Chi-square test, ANOVA

Table 3 Multivariate Analysis of Risk Factors Relationship mRNA Expression; $p 53$ and Bc/2 and VCAM1 Levels with the Incidence of Preeclampsia Based on Multiple Logistic Regression Analysis

\begin{tabular}{lcccc}
\hline \multicolumn{1}{c}{ Variable } & Coefficient B & SE & p Value & OR (95\% CI) \\
\hline$p 53(\mathrm{ng} / \mu \mathrm{L})$ & 2.572 & 1.010 & 0.011 & $13.09(1.81-94.70)$ \\
$B c / 2(\mathrm{ng} / \mu \mathrm{L})$ & 1.363 & 0.749 & 0.069 & $3.91(0.90-16.98)$ \\
VCAM-1 $(\mathrm{ng} / \mathrm{mL})$ & 2.820 & 0.809 & $<0.001$ & $16.77(3.44-81.82)$ \\
\hline Constant & -2.646 & & & \\
\hline
\end{tabular}

Accuracy of the Model $=74.2 \%$

Table 4 The Correlation between mRNA Expression; $p 53$ and Bcl2 with VCAM-1 Levels in Preeclampsia and Normal Pregnancy

\begin{tabular}{|c|c|c|c|c|}
\hline \multirow{3}{*}{ Correlation } & \multicolumn{4}{|c|}{ Group } \\
\hline & \multicolumn{2}{|c|}{ Preeclampsia $(n=31)$} & \multicolumn{2}{|c|}{ Control $(n=31)$} \\
\hline & $r$ & p Value & $\mathbf{r}$ & p Value \\
\hline p53 with VCAM-1 & -0.490 & 0.005 & -0.415 & 0.020 \\
\hline Bc/2 with VCAM-1 & -0.093 & 0.619 & -0.201 & 0.278 \\
\hline Ratio Bc/2/p53 with VCAM-1 & 0.541 & 0.002 & 0.099 & 0.595 \\
\hline
\end{tabular}


test, Pearson's correlation and the regression test (which is used to compare two groups of subjects or bivariate) as well as the multiple logistic regression test (multivariate). The data analysis was performed using SPSS ver. 13.0 at a 95\% confidence interval ( $p \leq 0.05)$.

\section{Results}

Identification of preeclamptic subjects $(n=31)$ were made based on preeclampsia clinical diagnosis which includes the presence of hypertension $(\geq 140 / 90 \mathrm{mmHg}$ ). Normortensive pregnant women were included as the control subjects $(n=31)$. The main clinical parameters include gestational age, body mass index, age, and parity (Table 1 ). During the period of July 2009 and April 2010, a continuous series of 31 preeclamptic patients were studied.

No significant differences were found between the preeclamptic and normal pregnancies in terms of gestational age, BMI, maternal age, and parity (Table 1). Therefore, the characteristics of both groups can be considered homogeneous and the results of subsequent examinations can be considered as comparable.

Based on the Chi-square test, a significant correlation was seen between the incidence of preeclampsia and VCAM-1(p=0.001), p53 mRNA expression $(p=0.010)$ and $B c / 2$ mRNA $(p=0.041)$, whereas the Fas $L$ mRNA expression showed no significant relationship with the incidence of preeclampsia $(p=0.300)$ (Table 2$)$. Multivariable tests were performed on variables that had a value of $p<0.25$ (Table 3 ).

Multiple logistic regression analysis showed that the most dominant molecule associated with the incidence of preeclampsia was VCAM$1(\mathrm{OR}=16.77)$, which indicates that the levels of VCAM-1 are not normal, showing a 17-fold higher incidence risk for preeclampsia than the normal levels of VCAM-1. This result shows that VCAM1 is the most dominant risk factor in predicting the incidence of preeclampsia $(p<0.001)$. For the preeclamptic group, there was a significantly negative correlation between the levels of $p 53$ and VCAM-1 ( $p=0.005$ and $r=0.490)$ which indicates a weak association. For the normal pregnancy group, there was a significantly negative correlation between $p 53$ and higher levels of VCAM-1 $(p=0.0200$ and $r=0.415)$, indicating a weak association. There was a negative but statistically insignificant correlation between the levels of $B c / 2$ and VCAM-1 ( $p=0.093$ and $r=0.619$ ) in the preeclamptic group, indicating that the power of the correlation is weak. For the normal pregnancy group, there was a negative correlation between the levels of $B C / 2$ and VCAM-1, but this correlation was not statistically significant $(p=0.278$ and $r=0.201)$, indicating that the correlation is very weak (Table 4). The correlation between the levels of $B C / 2 / p 53$ ratio and VCAM- 1 in the preeclamptic group was significantly positive $(p=0.002$ and $r=0.541$ ) which indicates a weak relationship. In the normal pregnancy group, there was no significant positive correlation $(p=0.595$ and $r=0.099)$, indicating that the strength of the correlation is very weak (Table 5).

\section{Discussion}

The symptoms of hypertension associated with preeclampsia is developed during pregnancy and disappear after birth. This condition suggested that the placenta plays an important role as a source of preeclampsia. There is growing evidence for the notion that the dysfunction of endothelial cells is the major contributor to preeclampsia. Although the mechanism of the activation of endothelial dysfunction is already well understood, there is evidence suggesting that leukocytes play a role in this destructive process. Endothelial dysfunction leads to increased levels of VCAM-1 in the blood or urine of women with preeclampsia several weeks before and during pregnancy. The mean levels of VCAM-1 in the preeclampsia group were higher $(1,077.63 \mathrm{ng} /$ $\mathrm{mL}$ ) than the controls $(823.99 \mathrm{ng} / \mathrm{mL}),(\mathrm{p}=0.006)$. VCAM-1 indicates the presence of inflammation in preeclampsia. The inflammation results from endothelial damage; therefore, VCAM-1 is a marker of endothelial damage. ${ }^{11}$ In our study, medium levels of VCAM-1 (>890.08 ng/mL) were not significantly associated with preeclampsia $(p=0.401)$. This result is understandable because there are many factors that trigger preeclampsia other than the endothelial damage. One of the factors that allegedly contribute to triggering the onset of preeclampsia is apoptosis as a result of placental hypoxia leading to placental ischemia.

Our study indicated that the levels of VCAM-1 were high $(>890.08 \mathrm{ng} / \mathrm{mL}$ ) in 23 preeclampsia individuals (74.2\%), compared to only 10 in the control group (32.3\%), whereas 8 individuals $(25.8 \%)$ of the preeclampsia case group and 21 individuals of the control group (67.7\%) showed low levels of VCAM-1 (<890.08 ng/mL). This result is consistent with the theory that placental ischemia plays a role in preeclampsia syndrome; whereas in preeclampsia, increased adhesion molecule expression in the maternal circulation and elevated levels of homocysteine are found. Elevated level of VCAM-1 is one of the 
characteristics of the endothelial dysfunction, resulting in a lack of uteroplacental perfusion. Uteroplacental insufficiency leads to the release of free radicals and induces hypoxia. Hypoxia is thought to cause the increased phosphorylation of $p 53$ if there is an increased metabolic process at the level of the p53 gene and reduces the role of MDM-2, which will ultimately enhance the role of $p 53$ in the apoptotic process. The relationship between $p 53$ mRNA expression and the incidence of preeclampsia was significant $(p=0.010$, Table 2$)$. These results are consistent with in vitro and in vivo models. ${ }^{6,12}$ The $p 53$ gene protects cells against DNA damage and plays a role in DNA repair. The loss or inactivation of p53 would result in the disruption of genetic equilibrium.

The relation between the level of $B c / 2$ mRNA expression and the incidence of preeclampsia (Table 2 ) in this study was significant $(p=0.041)$. This result is consistent with the theory that the pathway that is more involved in the hypoxic conditions in preeclampsia is the more dominant intrinsic pathway in which the expression of $B c / 2$ decreased to induce apoptosis. It has been hypothesized that hypoxia would cause the loss of $\mathrm{BCl} / 2$ and/or $\mathrm{BCl}-\mathrm{XL}$ from the mitochondrial membrane and these proteins would be replaced by proapoptotic proteins, such as Bak, Bax and Bim. Our results on $\mathrm{Bcl} 2$ are in agreement with the results from previous reports. . $^{13,14}$

The FasL/Fas pathway is one of the body's main pathways to control placental apoptosis. Extrinsic pathways are thought to be the pathogenesis of preeclampsia. As reported by Laskowska ${ }^{15}$, when apoptosis occurred in normal pregnancy, a more advanced stage of pregnancy was associated with a higher rate of apoptosis in placentas. In preeclamptic pregnancies, CD4+ $T$ cells produce more Th1 cytokines, such as IL2, IFN $\alpha$ and TNF $\beta$, which induce an increase in apoptosis. This result was shown by Zou et al. ${ }^{16}$ who showed that a large concentration of IFNa induced the increased expression of FasL/ Fas. ${ }^{16}$ The results of the multivariable analysis of the relationship between risk factors (Table $3)$. The mRNA expression levels of $p 53$ and
$B C / 2$ and VCAM-1 levels were associated with preeclampsia, and VCAM-1 was the primary risk factor in predicting the incidence of preeclampsia $(p<0.001)$.

The results of this study showed a significant negative correlation between the expression of p53 mRNA and VCAM-1 levels in both the preeclampsia and normal pregnancy groups. The possible absence of correlation between VCAM1 and p53 may be due to many other factors that cause endothelial dysfunction in addition to VCAM-1, such as LDL, ICAM1, PECAM1 and von Willebrand factor VIII. It was reported on a study that a significant increase in ICAM1 expression but not VCAM-1 expression was found in preeclampsia. This result is in contrast with reports by Ohtani et al. ${ }^{8}$ who showed that ICAM1, VCAM-1, E-selectin and PECAM1 levels were significantly elevated in preeclampsia. It is possible that these results could explain the negative correlation between the expression of $p 53$ and $B c / 2$ mRNA with VCAM-1 levels.

In summary, these results indicate a positive weak correlation between the $B c / 2 / p 53$ ratio and higher levels of VCAM-1 in the preeclamptic group. In the normal pregnancy group, there is a very weak positive correlation between the $B c / 2$ / p53 ratio and higher levels of VCAM-1. These results show that increases in the $B c / 2 / p 53$ ratio will be followed by elevated levels of VCAM1 in preeclampsia, in which the expression of p53 would affect the balance of Bcl2 and Bax, as an intrinsic pathway of apoptosis in the mitochondrial membrane and the occurrence of placental apoptosis resulting in hypoxia. Hypoxia will increase the levels of free radicals that cause damage to endothelial cells which is characterized by increased levels of VCAM-1.

\section{Acknowledgements}

We thank Prof. Hiroyuki Kuwano, MD., PhD., FACS., from Gunma University, Japan; Bethy S. Hernowo, MD., Ph.D., Ahmad Faried, MD., Ph.D., and Rizky Abdulah, Ph.D., from Universitas Padjadjaran, Bandung; Yelliantty from School of Life Science and Technology, Bandung Institute of Technology, Indonesia, for fruitful discussions.

\section{References}

1. Masuyama H, Nakatsukasa H, Takamoto N, Hiramatsu Y. Correlation between soluble endoglin, vascular endotel growth factor receptor-1, and adipocytokines in preeclampsia. J Clin Endocrinol Metab. 2007; 92(7):2672-9.

2. Savion S, Lepsky $E$, Orenstein $H$, Carp $H$,
Shepshelovich J, Torchinsky A, et al. Apoptosis in the uterus of mice with pregnancy loss. Am J Reprod Immunol. 2002;47(2):118-27.

3. Hat B, Lipniacki T. Single cell experiments and modelling of $\mathrm{p} 53 / \mathrm{Mdm} 2$ pathway. Proceedings of 23rd IFIP TC 7 Conference on System Modelling 
and Optimization; 2007 July 23-27; Cracow. Poland. Poland: IFIP; 2007.

4. Zhang Z, Wang H, Li M, Rayburn E, Agrawal S, Zang R. Novel Mdm2 p53-independent funtions identified through RNA silencing technologies. Ann N Y Acad Sci. 2005;1058: 205-14.

5. Kundaje A, Eisenman S. Modelling of the p53 pathway to cell cycle arrest and apoptosis: Relevance to cancer. In: Bower JM, Bolouri H, editors. Computational modeling of genetic and biochemical networks. Seattle: A Bradford book; 2001. p. 1-19.

6. Levy R. The role of apoptosis in preeclampsia. Isr Med Assoc J. 2005;7(3):178-81.

7. Haupt S, Berger M, Goldberg Z, Haupt Y. Apoptosis p53 network. J Cell Sci. 2003;116(Pt 20):4077-85.

8. Ohtani $S$, Kagawa $S$, Tango $Y$, Umeoka T, Tokunaga $\mathrm{N}$, Tsunemitsu $\mathrm{Y}$, et al. Quantitative analysis of p53-targeted gene expression and visualization of p53 transcriptional activity following intramural administration of adenoviral p53 in vivo. Mol Cancer Ther. 2004;3(1):93-100.

9. Mbazima VG, Mokgotho MP, February F, Ress DJG, Mampuru LJ. Alteration of Bax-to-Bcl2 ratio modulates the anticancer activity of methanolic extract of commelina benghalensis (commlinaceae) in jurkat T cells. Afr J Biotechnol. 2008;7(20):3569-76.

10. Das $H$, Koizumi T, Chakraborty $S$, Ichimura $T$, Hasegawa K, Nishimura R. Quantitation of
Fas and FasLigand gene expression in human ovarian, cervical and endometrial carcinomas using real-time quantitative RT-PCR. Br J Cancer. 2000;82(10):1682-8.

11. Kim SY, Ryu HM, Yang JH, Kim MY, Ahn HK, Lim HJ, et al. Maternal serum levels of VCAM-1, ICAM-1 and E-selectin in preelampsia. J Korean Med Sci. 2004;19(5):688-92.

12. Pham TD, Maclennan NK, Chiu CT, Laksana GS, Hsu $\mathrm{JL}$, Lane RH. Uteroplacental insufficiency increases apoptosis and alters $\mathrm{p} 53$ gene methylation in the full-term IUGR rat kidney. Am J Physiol Regul Integr Comp Physiol. 2003;285(5):R962-70.

13. DiFederico E, Genbacev O, Fisher SJ. Preeclampsia is associated with widespread apoptosis of placental cytotrophoblasts within the uterine wall. Am J Pathol. 1999;155(1):293-301.

14. Nomura K, Saito S, Ide K, Kamino Y, Sasahara $\mathrm{H}$, Nakamoto $\mathrm{T}$, et al. Caffeine suppresses the expression of the Bcl2 mRNA in BeWo cell culture and rat placenta. J Nutr Biochem. 2004;15(6):3429.

15. Laskowska M, Leszczynska-Gorzelak B, OleszczukJ. Maternal and umbilical soluble Fas concentration in normotensive and preeclamptic pregnancies. Inter J Gynecol Obstet. 2005;89(1):45-6.

16. Zou GM, Reznikoff-Etievant MF, Hirsch F, Milliez J. IFN- $\gamma$ induced apoptosis in mouse embryonic stem cells, a putative mechanism of its embryotoxicity. Develop. Growth Differ. 2000;42(3):257-64. 